\title{
Optimal Speed Control of Hybrid Electric Vehicles
}

\author{
Anil Kumar Yadav ${ }^{\dagger}$, Prerna Gaur*, Shyama Kant Jha*, J. R. P. Gupta*, and A. P. Mittal ${ }^{*}$ \\ ${ }^{\dagger}$ Dept. of Electronics and Instrumentation Engg., Meerut Institute of Eng. \& Technology Meerut, Uttar Pradesh, India \\ * Division of Instrumentation \& Control Engg., Netaji Subhas Institute of Technology, Dwarka New Delhi, India
}

\begin{abstract}
The main objective of this paper is to control the speed of Nonlinear Hybrid Electric Vehicle (HEV) by controlling the throttle position. Various control techniques such as well known Proportional-Integral-Derivative (PID) controller in conjunction with state feedback controller (SFC) such as Pole Placement Technique (PPT), Observer Based Controller (OBC) and Linear Quadratic Regulator (LQR) Controller are designed. Some Intelligent control techniques e.g. fuzzy logic PD, Fuzzy logic PI along with Adaptive Controller such as Self Organizing Controller (SOC) is also designed. The design objective in this research paper is to provide smooth throttle movement, zero steady-state speed error, and to maintain a Selected Vehicle (SV) speed. A comparative study is carried out in order to identify the superiority of optimal control technique so as to get improved fuel economy, reduced pollution, improved driving safety and reduced manufacturing costs.
\end{abstract}

Key Words: Fuzzy logic control, Linear Quadratic Optimal Controller, Observer Based Controller, PID Controller, Pole-Placement Technique, Self Organizing Controller, Vehicle

\section{INTRODUCTION}

In recent years increasing concern of environment and economy has made the use of electric vehicle indispensable and ubiquitous in nature. The exhaust emissions of the conventional internal combustion engine vehicles (ICEVs) are the major source of urban pollution that causes the green house effect, which in turn leads to global warming. Even from the economic standpoint that is inherent in the poor energy conversion efficiency of the internal combustion (IC) engines, electric vehicle is more viable. Though efficiency calculated on the basis of conversion from crude oil to traction effort at wheels for electric vehicles (EVs) is not significantly higher yet, it does make a difference. The regulation of emission due to power generation at remotely located plant is much easier than those emanating from IC engine vehicle that are individually maintained and scattered all over the world. Furthermore, electric power used for the battery of EVs can also be generated using non conventional sources which are environment friendly [1], [2]. Electric vehicles have no emissions and therefore are capable of tackling the pollution problem in an efficient way. Consequently electric vehicles are the only zero emissions vehicles (ZEVs) available now days. The limited range of battery powered electric vehicles led the researchers and auto industry players to search for alternatives. The assiduous and aggressive efforts by the industry led to the prodigious development of hybrid electric

\footnotetext{
Manuscript received Jan. 4, 2011; revised Mar. 11, 2011

Recommended for publication by Guest Associate Editor Chris Edrington.

$\dagger$ Corresponding Author: anilei007@gmail.com

Tel: +91-975846092, Meerut Institute of Engg. \& Technology

* Division of Instrumentation \& Control Engg., Netaji Subhas Institute of Technology, India
}

vehicles (HEVs).The HEVs use both electric machines and an IC engine for delivering the propulsion power [1], [2]. With the burgeoning popularity of EVs and HEVs in the market bewildering varieties of energy management system in the hybrid drive train is devised. As pioneers of intelligent energy management in HEVs some authors have proposed an extensive classification and overviews of state of the art control strategies for the same [2]-[7].

The modern electric vehicle performance depends very much on automation systems applied. The conventional control methods have been found not so adequate and many control problems have come up due to imprecise input output relation and unknown external disturbances. Many new controllers such as fuzzy logic controller (FLC) have been suggested in near past to address such problems. FLC provides an efficient method to handle inexact information on a basis of reasoning. With FLC it is possible to convert knowledge expressed in uncertain form to an exact algorithm. Application of FLC and self tuning fuzzy PID controller have been used for the design of four wheeled drive EV yaw stability and industrial hydraulic actuator respectively [8], [9]. A new scheme known as self organizing fuzzy logic controller for wheeled mobile rotor using evolutionary algorithm has been suggested by Kim et. al [10]. As fuzzy controller alone was not able to provide many features of adaptive controller both were together used for different control problems [11]-[14].

Next the state feedback control technique such as LQR controller of optimal control segment came up with beautiful features to improve dynamic as well as steady state performance [15]-[22]. The speed control in HEVs are mainly achieved controlling the servo motor which in turn controls the throttle position for smooth torque and speed control of 


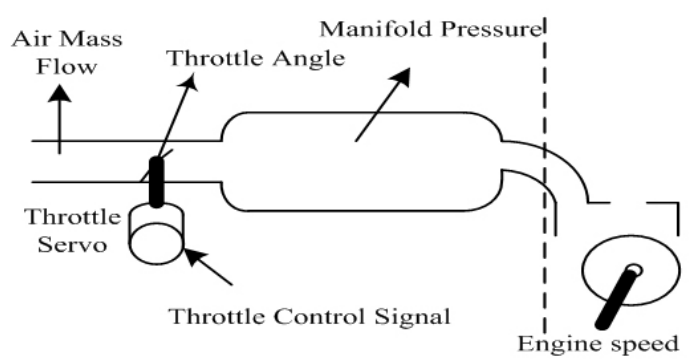

Fig. 1. Schematic diagram of the electronic throttle control.

TABLE I

NUMERICAL VALUES OF EV [21]

\begin{tabular}{|l|c|c|}
\hline Constant & Notation & Value (SI unit) \\
\hline Vehicle mass & $\mathrm{m}$ & $1000 \mathrm{~kg}$ \\
\hline Drag coefficient & $\alpha$ & $4 \mathrm{~N} /(\mathrm{m} / \mathrm{s})^{2}$ \\
\hline Engine force coefficient & $\gamma$ & $12500 \mathrm{~N}$ \\
\hline Engine idle force & $\mathrm{F}_{\mathrm{i}}$ & $6400 \mathrm{~N}$ \\
\hline Engine time constant & $\tau_{\mathrm{e}}$ & 0.2 second \\
\hline
\end{tabular}

HEVs. In controlling the throttle position by the proposed LQR controller, optimal current is drawn by the electric machine and drive which in turn optimizes the speed of the vehicle. Even as some authors have suggested the application of optimal control for other systems, some other authors have proposed other control technique for electric vehicle [23]-[28].

In this paper a comparative performance of controllers for HEVs are presented in order to identify the superior controller over other controllers designed in this paper.

\section{Model Description Of The Vehicle}

A schematic diagram of the electronic throttle control is given in Fig. 1 in which a DC servo motor is shown controlled by different controllers.

The dynamics of the vehicle [11], [21] are given as follows

$$
\begin{gathered}
m \frac{d v}{d t}=F_{e}(\theta)-\alpha v^{2}-F_{g} \\
\tau_{e} \frac{d F_{e}(\theta)}{d t}=-F_{e}(\theta)+F_{e 1}(\theta) \\
F_{e 1}(\theta)=F_{1}+\gamma \sqrt{\theta}
\end{gathered}
$$

$F_{e}=$ Engine force, a function of the throttle position $F_{g}=$ Gravity induced force, a function of the road grade $\theta=$ Throttle position, $v=$ Vehicle speed

\section{A. Assumption}

1) Gravity induced force $\left(F_{g}\right)$ is $30 \%$ of weight of vehicle.

2) Engine time constant commonly lie between 0.1 to 1 sec., here we take $0.2 \mathrm{~s}$.

The numerical value of the parameters used for analysis is shown in Table I.

By using (1), (2) and (3) design simulink model of vehicle that is shown in fig.2, (4) shows the state variable representation of vehicle and (5) shows the transfer function of vehicle.

$$
\begin{aligned}
& A=\left[\begin{array}{ll}
0 & 0.001 \\
0 & -5
\end{array}\right], B=\left[\begin{array}{l}
0 \\
8.29 * 10^{8}
\end{array}\right], C=\left[\begin{array}{ll}
1 & 0
\end{array}\right] \\
& D=[0]
\end{aligned}
$$

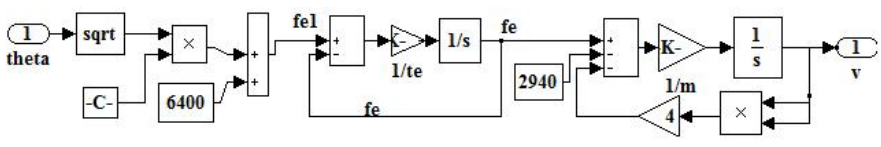

Fig. 2. Simulink model of vehicle.

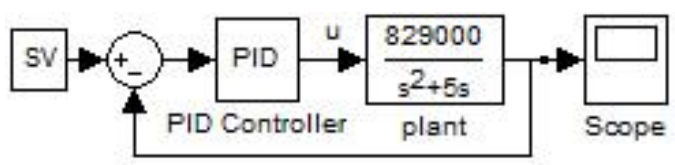

Fig. 3. Simulink model of plant with PID controller.

Transfer function:

$$
\frac{V(s)}{\theta(s)}=\frac{8.29 * 10^{5}}{s^{2}+5 s} .
$$

In order to see the relative effectiveness of different controllers to solve the problem of controlling the desired vehicle speed, here PID, PPT, OBC, SOC, FLC, and Linear Quadratic Regulator (LQR) Controller (Optimal), etc are taken into consideration.

\section{Analysis of Open Loop Stability [15]}

The characteristic equations of system described with (4) could be shown as $|\lambda I-A|=0$, whence we get the Eigen values of the open-loop system as $\lambda_{1}=0, \lambda_{2}=-5$.

\section{A. Analysis of Open-loop system Controllability and Observ- ability [15]}

The states equation of a linear time invariant (LTI) system is presented as $\dot{x}(t)=A x(t)+B u(t)$. In which, A denotes a $n \times n$ dimensional system matrix, B denotes a $n \times r$ dimensional input or control matrix, u denotes a $r \times 1$ dimensional input vector matrix. When the rank of matrix $M=$ $\left[\begin{array}{lllll}B & A B & A^{2} B & \ldots & A^{n-1} B\end{array}\right]$ is $\mathrm{n}$, the system is controllable. The matrix $\mathrm{M}$ of the system described with (4) could be shown as follows. $M=1 * 10^{9} \times\left[\begin{array}{ll}0 & 0.0008 \\ 0.83 & -4.145\end{array}\right]$. It is obvious that the system described with (4) is controllable, because order of matrix $\mathrm{M}$ is equal to rank of $\mathrm{M}$. The observable matrix is represented as $N=\left[\begin{array}{lllll}C & C A & C A^{2} & \ldots & C A^{n-1}\end{array}\right]^{T}$. The system is observable if the rank of matrix $\mathrm{N}$ is $\mathrm{n}$. The matrix $\mathrm{N}$ of system described by (4) could be shown as follows. $N=\left[\begin{array}{ll}1 & 0.000 \\ 0 & 0.001\end{array}\right]$. It is obvious that the system described with (4) is observable, because order of matrix $\mathrm{N}$ is equal to the rank of $\mathrm{N}$.

\section{PID CONTROL}

The transfer function of PID controller is given as

$$
C(s)=K_{P}+\frac{K_{I}}{s}+K_{d} s=K_{P}\left(1+\frac{1}{T_{I} s}+T_{d} s\right)
$$

Where: $K_{p}=$ Proportional Gain, $K_{i}=$ Integral Gain, $T_{i}=$ Reset Time $=K_{p} / K_{i}, K_{d}=$ Derivative gain, $T_{d}=$ Rate time or derivative time $=K_{d} / K_{P}$. Fig. 3 shows the simulink model of vehicle with PID controller. 


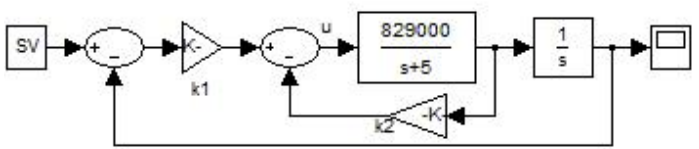

Fig. 4. Simulink model of State feedback controller via PPT.

\section{Modern Control Technique}

State-space approach has often been referred to as modern control design. The power of state variable technique is especially apparent when we need to design the controllers for system having more than one control input or sensed output.

\section{A. State Feedback Control}

Here prominently three state space design methods based on pole placement, observer and $L Q R$ based method are considered. In pole placement design we place all closed loop poles at desired location. The main goal of a feedback design is to stabilize if it is initially unstable or to improve the relative stability [20].

Consider the linear time invariant (LTI) system with nth -order state differential equation.

$$
\dot{x}(t)=A x(t)+B u(t) .
$$

In the state feedback design, the control signal input $u$ is realized as linear combinations of all the states, that is

$$
\begin{gathered}
u(t)=-k_{1} x_{1}(t)-k_{2} x_{2}(t)-\ldots-k_{n} x_{n}(t) \\
=k * x(t) \\
\quad k=k_{1}, k_{2} \ldots k_{n}
\end{gathered}
$$

$k$ is a constant state feedback gain matrix.

The closed loop system is describe by the state differential equation.

$$
\dot{x}(t)=(A-B k) x(t) .
$$

The characteristics equation of the closed loop system is [22].

$$
|s I-(A-B k)|=0
$$

The desired characteristics equation is

$$
\left(s-\lambda_{1}\right)\left(s-\lambda_{2}\right) \ldots \ldots\left(s-\lambda_{n}\right)=0
$$

Where $\lambda_{1}, \lambda_{2}, \ldots, \lambda_{n}$ are desired location of closed loop pole. The selection of desired closed loop poles requires a proper balance of bandwidth, overshoot, sensitivity, control effort etc. The elements of $\mathrm{k}$ are obtained by matching the coefficient of (11) and (12). Fig. 4 shows the simulink model of State feedback controller via PPT.

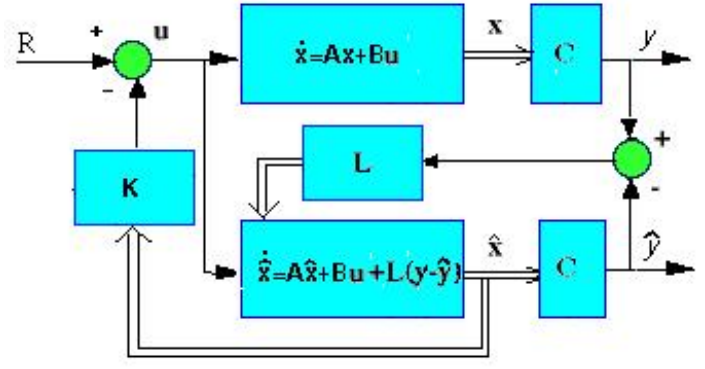

Fig. 5. State feedback controller with state observer (estimator).

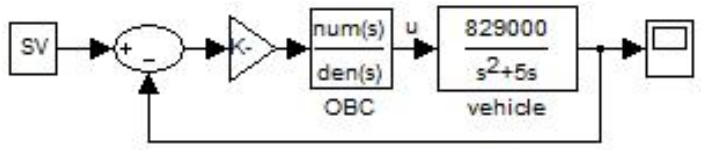

Fig. 6. Simulink model of OBC with plant.

\section{B. Observer-Based Controller}

A Device (or computer program) that estimates the state variable is called a state observer or simply an observer. Fig. 5 shows the state feedback control with state observer (estimator). It is also known as compensator [20].

The transfer function of OBC is given by [18], [20]

$$
D(s)=K(s I-A+B K+L C)^{-1} L
$$

\section{$\mathrm{L}=$ Observer gain matrix}

Simulink model of OBC shown in fig. 6.

\section{Linear Quadratic Optimal Controller [24]-[26]}

Here we shall consider an important class of optimal control problems known as linear regulator systems. Any problems having linear plant dynamics and quadratic performance criteria are referred to as linear regulator problem. The process to be controlled is described by the state equations.

$$
\dot{x}=A(t) x(t)+B(t) u(t) .
$$

Here the problem is to find an admissible control $\mathrm{u}^{*}$ that causes the above process to follow an admissible trajectory $\mathrm{x}^{*}$ that minimizes the performance measure.

$$
J=\frac{1}{2} x^{T}\left(t_{f}\right) S x\left(t_{f}\right)+\int_{t_{0}}^{t_{f}} \frac{1}{2}\left[x^{T} Q x+u^{T} R u\right] d t .
$$

$\mathrm{S}$ and $\mathrm{Q}$ are real symmetric positive semi definite matrices; $\mathrm{R}$ is real symmetric positive matrix.

We can get the state equation, costate equation, and other important equation by defining the Hamiltonian as

$$
\begin{aligned}
H(x(t), u(t), \lambda(t), t) & =g(x(t), u(t), t) \\
& +\lambda^{T}(t)[a(x(t), u(t), t)] .
\end{aligned}
$$

Using this notation we can write the necessary conditions as follows:

$$
\begin{aligned}
\dot{x}^{*}(t) & =\frac{\partial H}{\partial \lambda}\left(x^{*}(t), u^{*}(t), \lambda^{*}(t), t\right) \\
\dot{\lambda}^{*}(t) & =-\frac{\partial H}{\partial x}\left(x^{*}(t), u^{*}(t), \lambda^{*}(t), t\right)
\end{aligned}
$$




$$
0=\frac{\partial H}{\partial u}\left(x^{*}(t), u^{*}(t), \lambda^{*}(t), t\right)
$$

and

$$
\begin{aligned}
& {\left[\frac{\partial h}{\partial x}\left(x^{*}\left(t_{f}\right), t_{f}\right)-\lambda^{*}\left(t_{f}\right)\right]^{T} \delta x_{f}+} \\
& {\left[H\left(x^{*}\left(t_{f}\right), u^{*}\left(t_{f}\right), \lambda^{*}\left(t_{f}\right), t_{f}\right)+\frac{\partial h}{\partial t}\left(x^{*}\left(t_{f}\right), t_{f}\right)\right] \delta t_{f}=0}
\end{aligned}
$$
is

Here from the performance measure (15) the Hamiltonian

$$
\begin{aligned}
& H(x(t), u(t), \lambda(t), t) \\
& =\frac{1}{2} x^{T} Q x+\frac{1}{2} u^{T} R u+\lambda^{T} A x+\frac{1}{2} \lambda^{T} B u
\end{aligned}
$$

Using the equation (17) through (18) we get

$$
\begin{gathered}
\frac{\partial H}{\partial u}=0=R(t) u(t)+B^{T}(t) \lambda(t) \\
\frac{\partial H}{\partial u}=-\lambda=Q(t) x(t)+A^{T}(t) \lambda(t)
\end{gathered}
$$

with the terminal condition

$$
\lambda\left(t_{f}\right)=\frac{\partial h}{\partial x\left(t_{f}\right)}=S x\left(t_{f}\right)
$$

Thus we require that

$$
u(t)=-R^{-1}(t) B(t) \lambda(t)
$$

And we shall enquire whether we may convert this to a closed-loop control by assuming that the solution for the adjoint is similar to (22).

$$
\lambda(t)=P(t) x(t)
$$

Clubbing (27) with (20) and (26) we require that

$$
\dot{x}=A(t) x(t)-B(t) R^{-1} B^{T}(t) P(t) x(t)
$$

Also from (27) and (24) we require

$$
\dot{\lambda}=\dot{p} x+p \dot{x}=-Q x-A^{T} P x
$$

By combining (28) and (29) we have

$$
\left[\dot{P}+P A+A^{T} P-P B R^{-1} B^{T} P+Q\right] x=0
$$

Since this must hold for all non zero $\mathrm{x}(\mathrm{t})$, the term premultiplying $\mathrm{x}(\mathrm{t})$ must be zero. Thus the $\mathrm{P}$ matrix, which is a $n \times n$ symmetric matrix, must satisfy the matrix Riccati equation.

$$
-\dot{P}=P A+A^{T} P-P B R^{-1} B^{T} P+Q
$$

With a terminal condition given by (25) and (27).

$$
P\left(t_{f}\right)=s
$$

Thus we may solve the matrix Riccati equation backward in time from $t_{f}$ to $t_{0}$, storing the matrix.

$$
K(t)=-R^{-1}(t) B^{T}(t) P(t)
$$

We obtain a closed control form.

$$
u(t)=-R^{-1}(t) B^{T}(t) P(t) x(t) .
$$

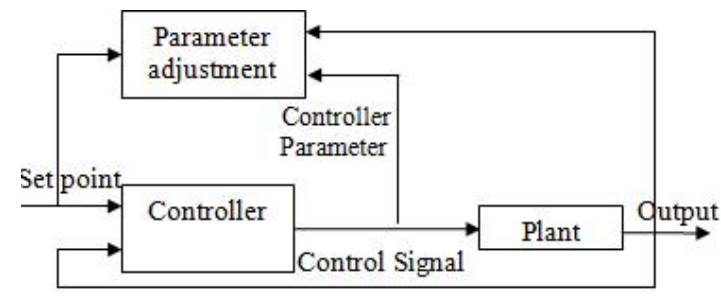

Fig. 7. Block diagram of Adaptive control systems.

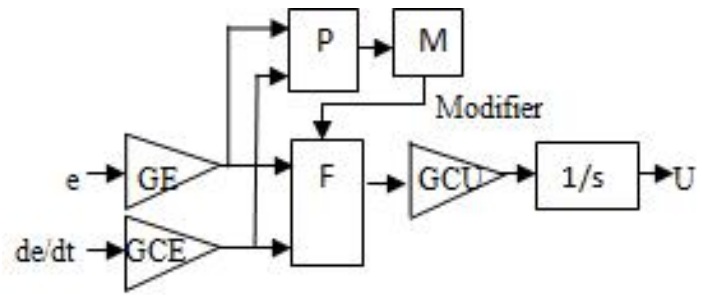

Fig. 8. Basic Structure of SOC [16].

This indicates that the optimal control law is a linear time varying function of the system states hence the measurement of all of the state variables must be available to implement the optimal control law. The (31) gives the final optimal control law. LQR [14] can be used to design the optimal controller to ensure the optimal speed tracking performance i.e. Speed tracking error $\left(V_{d}-V\right)$ is optimal. The Optimal LQR is developed using (31) and code is written using Mfile in MATLAB. The value of $K_{1}$ and $K_{2}$ for the model of optimal LQR are found using MATLAB command "care."

\section{SElf Organizing CONTROLler}

In order to build an accurate self-organizing controller, the auxiliary system should possess information on how the plant output varies with respect to the control signal for every possible operating region [20]. An adaptive controller is therefore intuitively a controller that can modify its behavior after changes in the controlled plant or in the environment. Fig. 7 shows the block diagram of adaptive control system and fig. 8 shows the basic structure of SOC.

In SOC the outer loop adjusts the controller lookup table $\mathrm{F}$ according to the performance measure in $\mathrm{P}$ fig. 9 shows the Simulink model of SOC.

In this paper Self Organizing Fuzzy Controller is designed and is tuned based on the Procyk and Mamdani Performance table (Table II).

\section{FUZZY LOGIC CONTROL}

In this paper design and investigate the performance of fuzzy logic controller (FLC) for a nonlinear vehicle model. The controller maintains a constant vehicle speed in spite of never ending changes in road grade, wind resistance, and other variables. Fig. 10 shows the block diagram of the vehicle with FLC, Fig.11 shows the structure of FLC.

The design of a FLC can be resumed to choosing and processing the inputs and outputs of the controller. For designing the FLC four components are used namely rule base, inference engine, fuzzification and defuzzification [18]. The inputs to the FLC; the error (e)

$$
e(k T)=r-y
$$


TABLE II

PERformance TABLE ADAPTED FROM PROCYK AND MAMdANi [16]

\begin{tabular}{|c|c|c|c|c|c|c|c|c|c|c|c|c|c|}
\hline E CE & -6 & -5 & -4 & -3 & -2 & -1 & 0 & 1 & 2 & 3 & 4 & 5 & 6 \\
\hline-6 & -6 & -6 & -6 & -6 & -6 & -6 & -6 & 0 & 0 & 0 & 0 & 0 & 0 \\
\hline-5 & -6 & -6 & -6 & -6 & -6 & -6 & -6 & -3 & -2 & -2 & 0 & 0 & 0 \\
\hline-4 & -6 & -6 & -6 & -6 & -6 & -6 & -6 & -5 & -4 & -2 & 0 & 0 & 0 \\
\hline-3 & -6 & -5 & -5 & -4 & -4 & -4 & -4 & -3 & -2 & 0 & 0 & 0 & 0 \\
\hline-2 & -6 & -5 & -4 & -3 & -2 & -2 & -2 & 0 & 0 & 0 & 0 & 0 & 0 \\
\hline-1 & -5 & -4 & -3 & -2 & -1 & -1 & -1 & 0 & 0 & 0 & 0 & 0 & 0 \\
\hline 0 & -4 & -3 & -2 & -1 & 0 & 0 & 0 & 0 & 0 & 1 & 2 & 3 & 4 \\
\hline 1 & 0 & 0 & 0 & 0 & 0 & 0 & 1 & 1 & 1 & 2 & 3 & 4 & 5 \\
\hline 2 & 0 & 0 & 0 & 0 & 0 & 0 & 2 & 2 & 2 & 3 & 4 & 5 & 6 \\
\hline 3 & 0 & 0 & 0 & 0 & 2 & 3 & 4 & 4 & 4 & 4 & 5 & 5 & 6 \\
\hline 4 & 0 & 0 & 0 & 0 & 4 & 5 & 6 & 6 & 6 & 6 & 6 & 6 & 6 \\
\hline 5 & 0 & 0 & 0 & 0 & 2 & 3 & 6 & 6 & 6 & 6 & 6 & 6 & 6 \\
\hline 6 & 0 & 0 & 0 & 0 & 0 & 0 & 6 & 6 & 6 & 6 & 6 & 6 & 6 \\
\hline
\end{tabular}

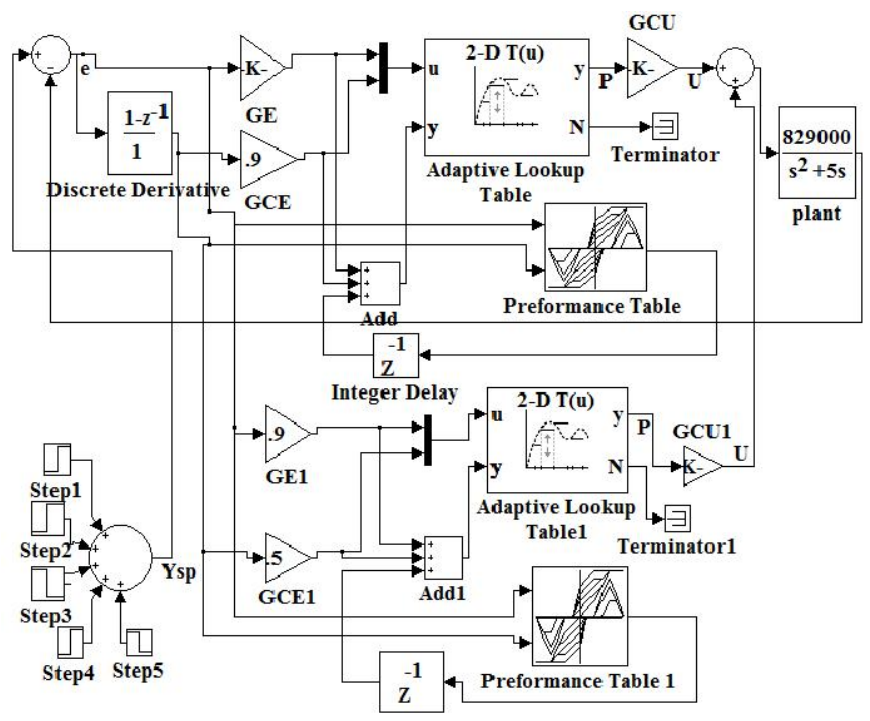

Fig. 9. Simulink model of SOC.

Change in error (ce)

$$
c e(k T)=(e(k T)-e(k T-T)) / T
$$

and output variable is the throttle position

$$
u=\theta .
$$

The universe of discourse of the variables cover a range of $[-2,2]$ for error, $[-4,4]$ for change in error and $[-10,10]$ for output. A standard choice for the triangular membership functions is used with three membership functions for the three fuzzy variables (meaning $9=3^{2}$ rules in the rule base). The resulting rule base is shown in the Table III.

Note that we are using "NB" as an abbreviation for "negative big in size" and so on for the other variables. Such abbreviations help keep the linguistic descriptions short yet precise:

"N" to represent "negative"

TABLE III

FUZZY RULE BASES FOR FLC

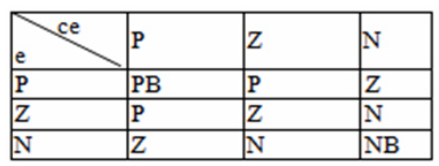

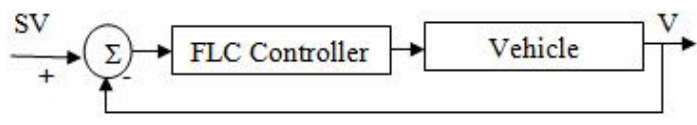

Fig. 10. Block diagram of the vehicle with FLC.

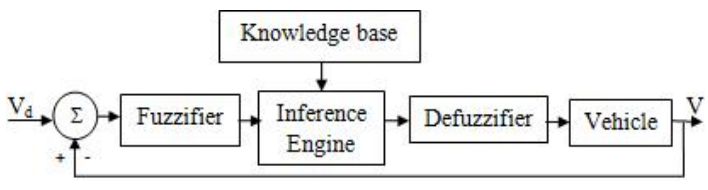

Fig. 11. Basic structure of FLC.

"Z" to represent "zero"

"P" to represent "positive"

"PB" to represent "positive big"

To obtain the crisp output, the centre of gravity (COG) defuzzification technique is used.

The controller does this by comparing the commanded speed with the actual speed. The error change is the difference in error from one sample period to the next. If the error is a small positive number i.e. vehicle speed is slower than that set value, the controller needs to slightly increase the throttle angle in order to speed up the vehicle appropriately [12]. If both current error and error change are positive, the vehicle is going too slowly and decelerating. In this case, the controller needs to increase the throttle angle by a larger amount to achieve the desired speed. Such specifications are called fuzzy rules. The output represents a fuzzy logic specification of how much to change the throttle position. Fig. 12 and fig. 13 shows the simulink model of fuzzy logic PD and fuzzy logic PI controller respectively.

\section{ViII. Simulation Results And Discussion}

In this section the results obtained from the open loop system without controller and closed loop system with various controllers are presented. The response of the system with controllers such as PID, Optimal LQR, OBC, SOC, and FLC are presented and compared. Fig. 14 shows the Open loop step response that shows the system is unstable as it is not converging.

Fig. 14 shows the response with PID Controller. Here PID controller is tuned by using both Hand-tuning rule [17] and Ziegler-Nichols method the corresponding value of controller parameters are given in Table IV.

PID controller is tuned by two method Ziegler-Nichols and Hand-tuning rule that gives $46.7 \%$ and $15.6 \%$ Max overshoot respectively. Tuning by hand tuning rule gives better performance.

Fig. 16 shows the vehicle response for state feedback (Pole-Placement) and OBC. PPT has desired characteristic equation $s^{2}+8 s+16=0$ i.e. desired pole at location -4 , 4. The value of $K_{1}$ and $K_{2}$ are given in Table V. In OBC $L=\left[\begin{array}{l}0.003 \\ 1.000\end{array}\right]$, using (13) the transfer function of $\mathrm{OBC}$ is

TABLE IV

PID CONTROLLER PARAMETERS

\begin{tabular}{|l|l|l|l|}
\hline Tuning Method & KP & KI & KD \\
\hline Ziegler-Nichols & $1.22^{*} 10^{-4}$ & $3.47^{*} 10^{-4}$ & $6.8^{*} 10^{-6}$ \\
\hline Hand-tuning & 0.01 & 0.03 & 0.001 \\
\hline
\end{tabular}




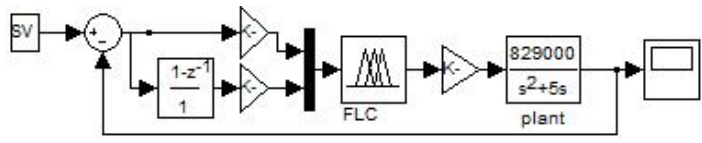

Fig. 12. Simulink model of fuzzy logic PD control.

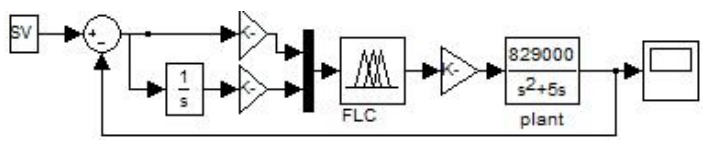

Fig. 13. Simulink model of fuzzy logic PI control.

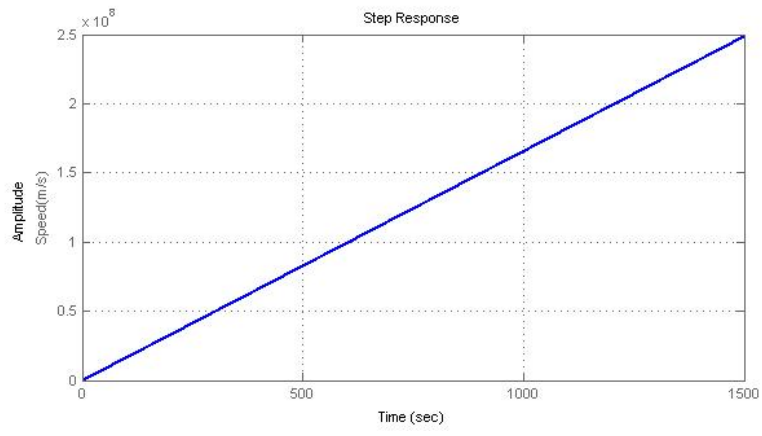

Fig. 14. Open loop step response of vehicle.

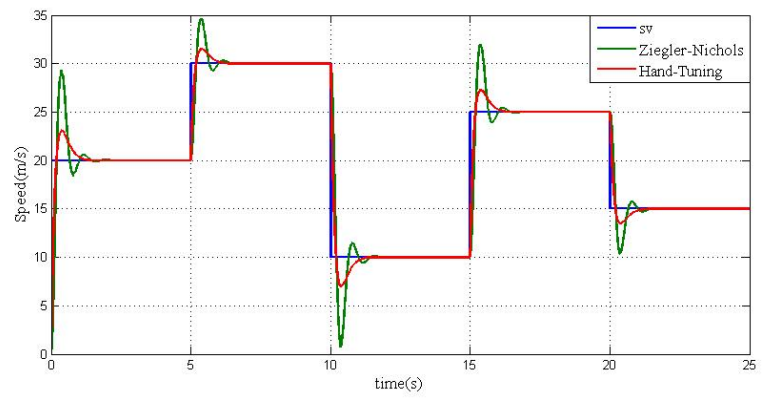

Fig. 15. Vehicle response with PID Controller.

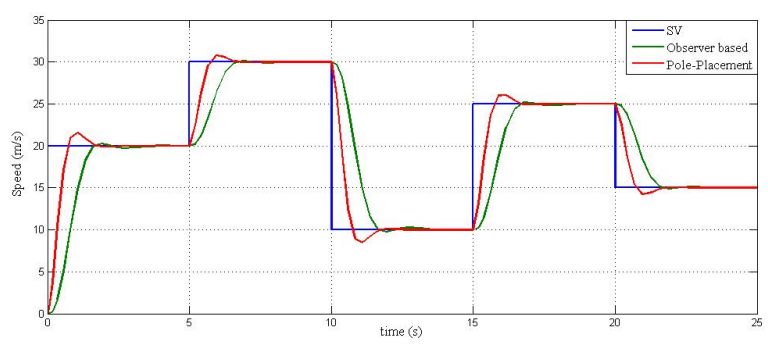

Fig. 16. PPT and OBC response for vehicle.

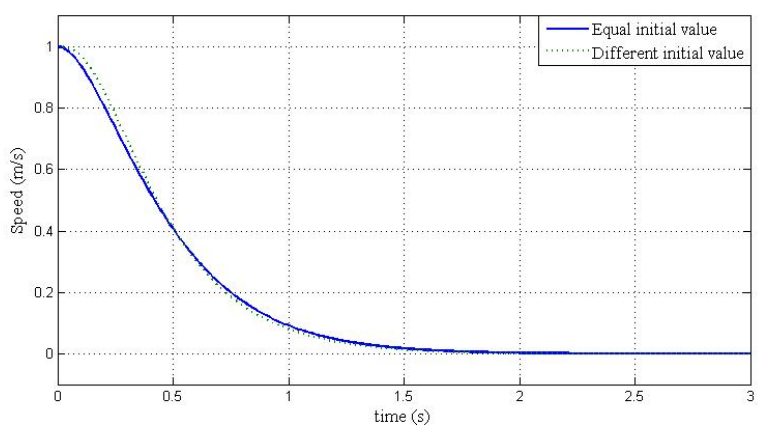

Fig. 17. Initial condition response.

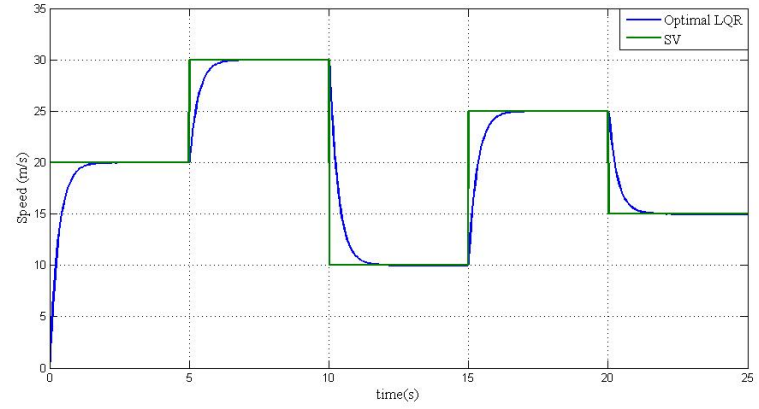

Fig. 18. Optimal LQR response for vehicle.

TABLE V

STATE FEEDBACK GAIN PARAMETERS

\begin{tabular}{|c|c|c|}
\hline Techniques & $K_{1}$ & $K_{2}$ \\
\hline PPT & $0.193 * 10^{-4}$ & 0 \\
\hline Optimal LQR & $0.3162^{*} 10^{-3}$ & $0.1 * 10^{-3}$ \\
\hline
\end{tabular}

$D(s)=\frac{5.79 * 10^{-8} * s+3.088 * 10^{-7}}{s^{2}+5 s+16}$. It is clear that OBC gives better response. OBC improves the overshoot and settling time. These Response tracks the given set value (desired speed).

Initial condition response for an OBC is shown in fig.17. In this two responses are given.

$(A)_{q(0)}=x(0)=\left[\begin{array}{l}1 \\ 0\end{array}\right]$, it means that both observer and plant (vehicle) have same initial state.

$(B)_{q(0)}=\left[\begin{array}{l}0 \\ 0\end{array}\right], x(0)=\left[\begin{array}{l}1 \\ 0\end{array}\right]$, it means that both observer and plant (vehicle) have different initial state.

In LQR $Q=\left[\begin{array}{ll}0.1 & 0.00 \\ 0 & 0.01\end{array}\right], R=10 * 10^{5}$. The value of $K_{1}$ and $K_{2}$ are given in Table V. Fig. 18 shows the Optimal LQR Control response for $\mathrm{EV}$, which optimizes system performance and gives the best result in comparison with other control techniques as seen.

Fig. 19 shows the SOC response, where it takes comparatively longer time for controlling the vehicle. Fig. 20 shows the fuzzy logic PD and fuzzy logic PI response. In fuzzy logic PD overshoot occurs and settling time of both fuzzy logic controllers is nearly same.

Fig. 21 shows the combined response of all controllers for making the comparison among them and Table VI shows the performance index of these controllers for unit step input.

Fig. 22 represents the enlarged view of Fig. 21. The performance index shown in Table VI is made by using Fig. 22.

On the basis of Fig. 22 and Table VI the optimal LQR has got least max. Overshoot, settling time and steady state error, i.e. $0.03 \%$, $1 \mathrm{sec}$., $0.05 \%$ respectively. The rise time for LQR controller is $1 \mathrm{sec}$. it is due to the negligible disturbance after

TABLE VI

PERFORMANCE INDEX OF CONTROLLERS FOR UNIT STEP INPUT

\begin{tabular}{|c|c|c|c|c|}
\hline Controllers & $\begin{array}{c}\% \text { Max } \\
\text { overshoot }\end{array}$ & $\begin{array}{c}\text { Settling } \\
\text { time(s) }\end{array}$ & $\begin{array}{c}(\%) \\
\text { Steady } \\
\text { state Error }\end{array}$ & $\begin{array}{c}\text { Rise } \\
\text { time(s) }\end{array}$ \\
\hline PID & 15.6 & 0.79 & 0.15 & 0.19 \\
\hline PPT & 8.10 & 1.29 & 0.5 & 0.72 \\
\hline OBC & 1.31 & 1.87 & 0.1 & 1.64 \\
\hline Optimal LQR & 0.03 & 1 & 0.05 & 1 \\
\hline SOC & 11.7 & 9.55 & 1.5 & 2.63 \\
\hline Fuzzy PD & 2.2 & 1.5 & 0.3 & 1.15 \\
\hline Fuzzy PI & 0.6 & 2.1 & 0.1 & 1.7 \\
\hline
\end{tabular}




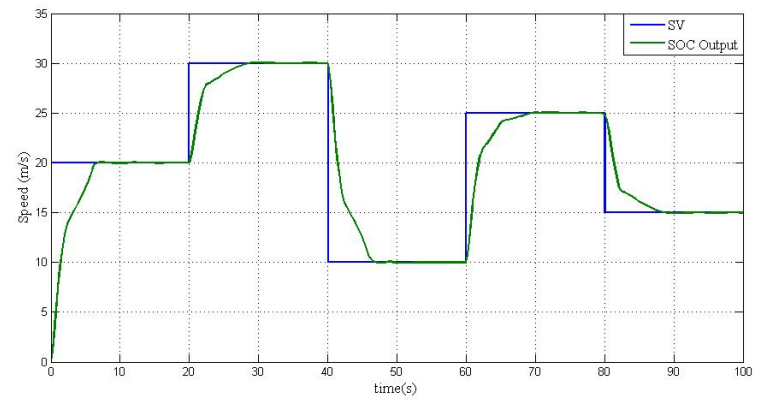

Fig. 19. SOC response for vehicle.

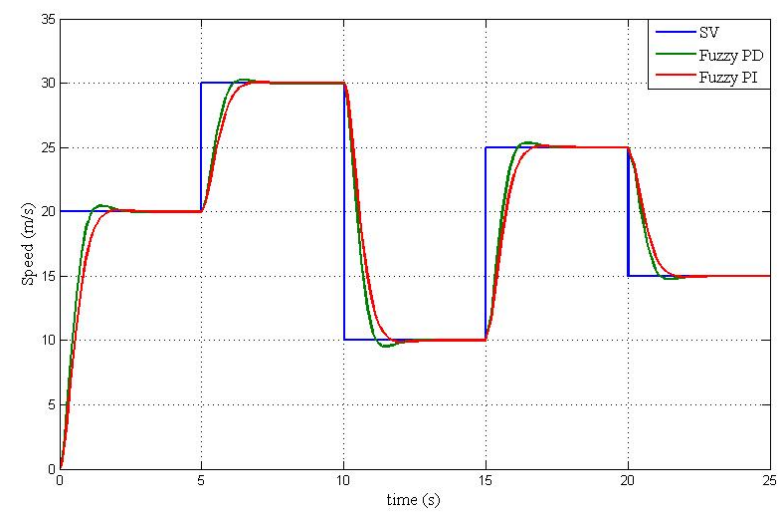

Fig. 20. Fuzzy logic PD and Fuzzy logic PI response for vehicle.

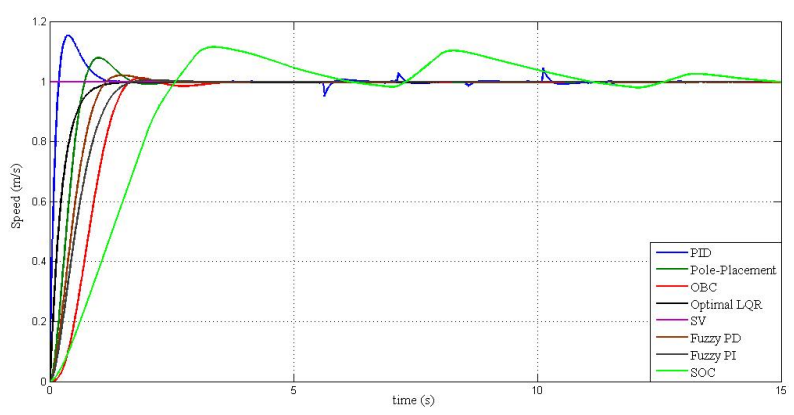

Fig. 21. Unit step response of all controller.

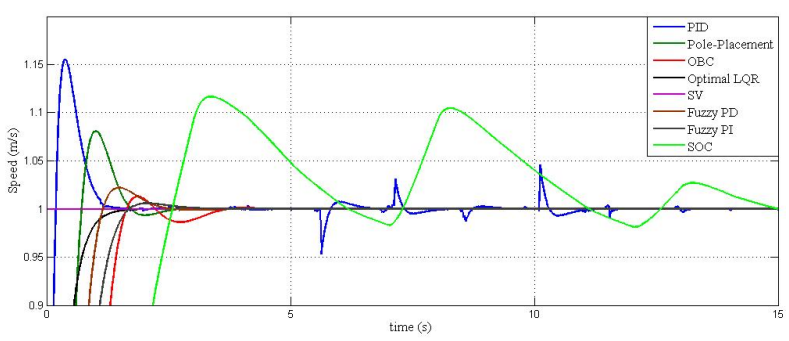

Fig. 22. Unit step response of all controller in enlarged form. settling once. Hence optimal LQR gives better performance index in comparison with other designed controllers i.e. PPT, OBC, PID, FLC and SOC etc.

\section{CONCLUSION}

A comparative analysis of all the controllers applied to control the speed of nonlinear hybrid electrical vehicle, vividly shows that LQR Optimal controller gives better performance result in all respect among all the controllers considered. The maximum overshoot and settling time in achieving the desired speed being the least the current and torque will also be optimized and for that matter the battery operation of such vehicles will be optimal. We may conclude that from the standpoint of transient and steady state response the LQR technique gives optimal performance and is sine qua non. LQR control technique may be applied to other similar nonlinear systems for performance optimization. Vehicle drive train efficiency may be improved with the LQR optimal Controller. Fuel efficiency of EV may also be optimized with may be taken up future research direction.

\section{REFERENCES}

[1] I. Husain, Electric and Hybrid Vehicles, Design Fundamentals, 2nd edition, CRC Press, Taylor and Francis Group, NewYork, Chap. 1, 2011.

[2] K. T. Chau, C. C. Chan, and C. Liu, "Overview of permanent magnet brushless drives for electric and hybrid electric vehicles," IEEE Trans. Ind. Electron., Vol. 55, No. 6, pp. 2246-2257, Jun. 2008.

[3] Z. Lubis, A. N. Abdalla, Mortaza and R. Ghon, "Mathematical modelling of three phase induction motor coupled to DC motor in hybrid electric vehicle," American Journal of Engineering and Applied Sciences, Vol. 2, No. 4, pp. 715-719, 2009.

[4] C. Zhang, Z. Bai, B. Cao and J. Lin, "Simulation and experiment of driving control system for electic vehicle," International Journal of Information and System Sciences, Vol. 1, No. 3-4, pp.283-292, 2005.

[5] F. R. Salmashi, "Control strategies for hybrid electric vehicle; evolution, classification, comparison and future trends," IEEE Trans. Vehicular Technology, Vol. 56, No. 5, pp. 2393-2404, Sep. 2007.

[6] Z. Preitl, P. Bauer, and J .Bokor, "Cascade control solution for traction motor for hybrid electric vehicles," Acta Polytechnica Hungarica, Vol. 4, No. 3, 2007.

[7] Yoichi Hori, "Motion control of Electric Vehicles and Prospects of Supercapacitors," IEEJ Transaction on Electrical and Electronic Engineering, Vol. 4, pp. 231-239, 2009.

[8] Zulfatman and M. F. Rahmat, "Application of self tuning fuzzy PID controller on industrial hydraulic actuator using system identification approach," International Journal on Smart Sensing and Intelligent system, Vol. 2, No. 2, Jun. 2009.

[9] L. Feiqiang, W. Jun, and L. Zhaodu, "Fuzzy logic based controller design for four-wheel-drive electric vehicle yaw stability enhansement," in Proc. Sixth International Conference on Fuzzy Systems and Knowledge Discovery, Vol. 4, 2009.

[10] S. H. Kim and C .Park, "A self organising fuzzy controller for wheeled mobile robot using evolutionary algorithm," IEEE Trans. Ind. Electron. Vol. 48, No. 2, pp. 467-474, Apr. 2001.

[11] K. M. Junaid and S. Wang, "Automatic Cruise control modeling- a lattice pwl approximation approach," in Proc. the IEEE ITSC, pp. 1370-1375, Sep. 2006.

[12] R. Mayr, and O. Bauer, "Safety issues in intelligent cruise control," in Proc. IEEEIntelligent Transportation Systems, pp. 970-975, 1999.

[13] A. Trebi-Ollennu and J. M. Dolan, "Adaptive fuzzy throttle control for an all terrain vehicle," in Proc. Robotics Institute, Paper 198, Oct. 1999.

[14] X. Liu, Q. Huang, Y. Chen, and J. Li, "Nonlinear modeling and optimal controller design for radar servo system," Third International Symposium on Intelligent Information Technology Application, 2009.

[15] L. Guo, Q. Liao, S. Wei, and Y. Zhuang, "Design of linear quadratic optimal controller for bicycle robot," in Proc. the IEEE International Conference on Automation and Logistics Shenyang, 2009.

[16] J. Jantzen, Foundation of Fuzzy Control, John Willy and Sons, Ltd., Chap. 6, 2007. 
[17] M. Namazov, "DC motor position control using fuzzy proportionalderivative controllers with different defuzzification methods," Turkish Journal of Fuzzy Systems An Official Journal of Turkish Fuzzy Systems Association, Vol. 1, No. 1, pp. 36-54, 2010.

[18] K. T. Oner, E. Cetinsoy, E. Sirimoglu, C. Hancer, T. Ayken, and M. Unel, "LQR and SMC stabilization of a new unmanned aerial vehicle" World Academy of Science, Engineering and Technology 58, 2009.

[19] L. Feiqiang, W. Jun, L. Zhaodu, "On the vehicle stability control for electric vehicle based on control allocation," IEEE Vehicle Power and Propulsion Conference (VPPC), pp. 1-5, 2008.

[20] M. Gopal, Digital Control and State Variable Methods Conventional and Intelligent Control System, Tata Mcgraw Hill Education Pte. Ltd., Third Reprint, Chap. 7, 2009.

[21] J. Yen and R. Langari, Fuzzy Logic Intelligence, Control, And Information, pearson education (Singapore) Pte.Ltd., Fourth Indian Reprint, Chap. 8, 2005.

[22] A. Kakilli, Y. Oguz, and H. Çalik, "The modelling of electric power systems on the state space and controlling of optimal lqr load frequency," Journal of Electrical \& Electronics Engineering, Vol. 9, No. 2, pp. 977982, 2009.

[23] L. Gollman, D. Kern, and H. Maurer, "Optimal control problems with delays in state and control variables subject to mixed control-state constraints," Journal of Optimal Control Applications and Methods, Vo. 30, pp. 341-365, 2009.

[24] I. R. Peterson, "Robust $H^{\infty}$ control of an uncertain system via a strict bounded real output feedback controller," Journal of Optimal Control Application and Methods, Vol. 30, pp. 247-266, 2009.

[25] D. E. Kirk, Optimal Control, Prentice Hall Inc, Chap. 5, 1970.

[26] P. P. Mohanlal, M. R Kaimal, and S. Dasgupta, "Exact fuzzy modeling and optimal control of a launch vehicle in the atmospheric phase," Seventh lnternational Conference on Control Automation, Roboties and Vision (ICARCV'OZ), Dec. 2002.

[27] C. Mi, H. Lin, and Y. Zhang, "Iterative learning control of antilock braking of electric and hybrid vehicles," IEEE Trans. Veh. Technol., Vol. 54, No. 2, pp. 486-494, Mar. 2005.

[28] S. Omatu, M. Yoshioka, and T. Kosaka, "PID control of speed and torque of electric vehicle," Third International Conference on Advanced Engineering Computing and Applications in Sciences, 2009.

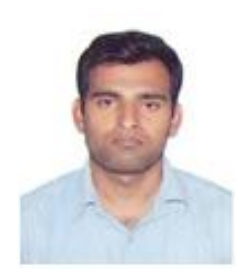

Anil Kumar Yadav was born in Jalalpur, Pratapgarh, (UP), India. He received his B.Tech in Electronics and Instrumentation Engineering from Hindustan College of Science and Technology Mathura (Uttar Pradesh Tecchnical University Lucknow) (UP) in 2007, M.tech from Netaji Subhas Institute of Technology, New Delhi, in 2010. He is Senior Lecturer in the Electronics and Instrumentation Engineering Department at Meerut Institute of Engg. and Technology Meerut. His research interests are in the areas Design of Fuzzy logic Controller, Optimal Control and Adaptive Control.

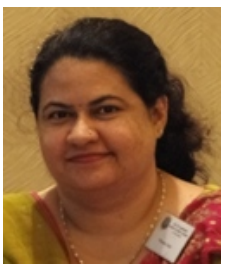

Prerna Gaur received her B.Tech and M.Tech in 1988 and 1996 from G.B. Pant College of Technology, Uttaranchal, India and Delhi College of Engineering, Delhi University, India. She is $\mathrm{PhD}$ in the field of AI based Motion Control of PMSM. She joined the industry in 1989 and Delhi College of Engineering as a Lecturer in 1994. She is an Assistant Professor in the Instrument and Control Engineering Division at Netaji Subhas Institute of Technology, Delhi University since 1998. She is a Life Member of the Indian Society for Technical Education (ISTE) and Senior Member of Institute of Electrical and Electronics Engineers (IEEE).

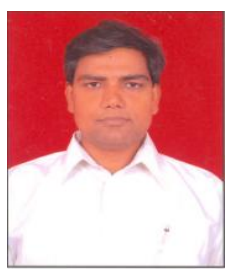

Shyama Kant Jha received his B.Sc.(Engg.) degree in Electrical Engineering from Bhagalpur College of Engineering, Bhagalpur and M.E. degree in Control \& Instrumentation from Delhi College of Engineering, Delhi University in 1994 and 2003 respectively. He joined the industry in 1995 and Netaji Subhas Institute of Technology (NSIT) as a Lecturer in 1999. Currently he is holding the post of Assistant Professor in the Instrumentation \& Control engineering Department at N.S.I.T, New Delhi. His research interests include optimal control, robust control, electric drives etc. He is a Life Member of the Indian Society for Technical Education (ISTE)

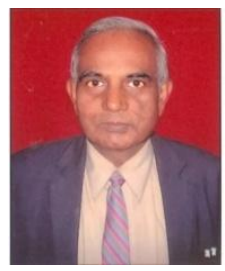

J. R. P. Gupta received his B.Sc. (Engg.) Degree in Electrical Engineering from Muzaffarpur Institute of Technology, Muzaffarpur and Ph.D from University of Bihar in 1972 and 1983 respectively. After serving Post and Telegraph Department, Government of India for nearly three years, he joined M.I.T. Muzaffarpur as Assistant Professor in 1976. He then switched over to R.I.T. Jamshedpur in 1986 and then to N.S.I.T, New Delhi in 1994 where currently he is holding the post of Professor and Head of the Department, Instrumentation and Control Engineering, University of Delhi. His research interest include power electronics, electric drives, control theory, intelligent instrumentations etc. He has been awarded K.S. Krishnan memorial award for the best system oriented paper by Institute of Electronics and Telecommunication Engineers (India), in 2008. $\mathrm{He}$ is senior member of IEEE.

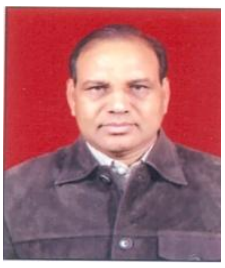

A. P. Mittal received his BE (Hons.) in Electrical Engineering from M.M.M.Engineering College, Gorakhpur (UP) in 1978, ME from University of Roorkee in 1980 and $\mathrm{PhD}$ from IIT, Delhi in 1991. He became an Assistant Professor in REC Kurukshetra and joined REC Hamirpur in 1989. He was a Professor and Head in CRSCE Murthal, Haryana from 1997 to 2001. He is HOD of Instrumentation and Control Engineering at Netaji Subhas Institute of Technology, New Delhi since 2001. He is a Life Member of the Indian Society for Technical Education (ISTE) and Senior Member of Institute of Electrical and Electronics Engineers (IEEE). 